\title{
EFFECT OF PRE-COOLING PROCESS ON SAFE STORAGE OF PEACH FRUITS STORED UNDER DIFFERENT STORAGE CONDITIONS \\ El-Kholy, M. M. ${ }^{1}$; H.E. Abd- Alla ${ }^{2}$ and M. Sh. Radwan ${ }^{3}$ \\ 1 Agric. Crops Agric. Eng. Res Institute. \\ 2 Agric. Eng., Fac. of Agric., Mansoura Univ. \\ ${ }^{3}$ Ministry of Agriculture, Egypt.
}

\begin{abstract}
A study was carried out to test and evaluate a portable pre-cooling unit. The effect of pre-cooling process on safe storage of the pre-cooled peach in comparison with the none cooled samples were also determined during storage process under two different storage conditions (cooled and room storage). The laboratory experiments were conducted at three different levels of air temperature $\left(4,7\right.$ and $\left.10^{\circ} \mathrm{C}\right)$, three levels of air velocity $(3.7,4.8$ and $5.4 \mathrm{~m} / \mathrm{s})$, three levels of packages vents percentage $(4,6$ and $8 \%)$ and two volumes of fruits (medium and large). The results showed rapid drop in peach temperature at the beginning of cooling process and the cooling rate starts to decline as the product temperature approached the final temperature. Also, the temperature of the peach fruits at the end position of the cooling chamber was always higher than that of the middle and front as well. The values of cooling coefficient (C) increased with the increase of air velocity $(V)$, increase of packages vents percentage, decrease of fruit volume and decrease of cooling air temperature. While, the seven-eighth and half cooling times decreased with the increase of air velocity and the packages vents percentage and they were increased with the increase of the medium air cooling temperature and increase of the product volume. The storage experiments showed that, the pre-cooled peach fruits recorded lower loss in water content, lower percentage of defects, and higher fruit firmness in comparison with the none cooled samples stored under the two storage conditions.
\end{abstract}

\section{INTRODUCTION}

Quality of fruits and vegetables, as in other products, is that combination of characteristics which makes them desirable to the buyer or consumer. Fruits and vegetables are ordinarily chosen by appearance because other methods which are used to determine quality are rarely available to the casual purchaser thus, to the vendor of fruits and vegetables. Such factors as grade, shape, color, and free from external defects are of compelling importance. In the next decade, it is expected that there will be a growing interest for high quality and full flavor fresh products. To satisfy this demand, post-harvest techniques must be improved to maintain the quality and to extend the shelf life of fresh fruits and vegetables, (Mitchell, 1992).

In Egypt, Peach fruits harvested during March- Julie season in which they are available in plenty. The planted area of peach is 83,703 fadden and the mass production is about 425,273tons (M.O.A, 2008). According to Kader (1993) peach classed as highly perishable climacteric crop. This type of fruits is highly deteriorate after harvest due to the high respiration rate which influenced by temperature. So it is important to immediately reduce the product temperature after harvest in order to reduce metabolic changes Shewfelt (1986). 
Pre-cooling is the removal of field heat from freshly harvested produce in order to slow down metabolism and reduce deterioration prior to transport or storage Ryall and Pentzer (1982).

There are varieties of pre-cooling techniques available for use in the horticultural industry. The principal methods of pre-cooling highly perishable produce include room cooling, hydro-cooling, forced air cooling, package icing, vacuum cooling and cryogenic cooling, with many variations and alterations within these techniques, Brosnan and Da- Wen (2001).

Forced air or pressure cooling is a modification of room cooling and is accomplished by exposing packages of produce to higher air pressure on one side than on the other, Fraser(1992).

Cooling rate is usually described in terms of half or seven-eighth cooling time. These values remain constant for a given system. The seveneighth cooling time $\left(T_{7 / 8}\right)$ is the time needed to decrease temperature difference from initial product temperature to cooling air by $7 / 8$. This value is an economical breakpoint for product cooling (Talbot and Chau, 1991).

Jordan et al. (1991) studied that effect of cooling delays on peach quality to provide a method for evaluating the economic impact of delayed cooling in peaches. Values of peach quality characteristics (size, damage, ground color, firmness and maturity) were estimated at the warehouse and retail stage. They found that at both the warehouse and consumer levels a 2 hours cooling delay produced higher economic returns than immediate cooling or cooling after 4-24h.

A portable forced-air cooling unit for fruit and vegetables was designed and construction by Talbot (1993). The Trailer-mounted cooling unit utilized two $10.5 \mathrm{~kW}$ (3-t) packaged air conditioner units, a high pressure blower, and a self-constructed cooling chamber. The quest cooling system was used to cool some fruits and vegetables and a comparison study between the suggested cooling system and the room cooling was done, the obtained results showed the suitability of the new system for cooling fruits and vegetables with keeping its quality during cooling and storage time.

The present study aims to test and evaluate a portable pre-cooling unit for pre-cooling of peach under different operational conditions. The quality changes and the safe storage period of the per-cooled peach were also determined under different storage conditions.

\section{MATERIALS AND METHODS}

This study was carried out at the experimental Station of Rice Mechanization Center (R.M.C.), Meet El-Deyba, Kafr El-Sheikh Governorate during 2007 and 2008 seasons. The experimental work was preceded in two stages; the first stage included developing and testing a portable pre-cooling unit for peach cooling. While, the second stage included storage of the precooled peach in a refrigerated room and in ambient condition to asses some quality changes of the pre-cooled fruits in comparison with the none cooled samples. 


\section{Components Of The Pre-Cooling Unit:}

Fig. (1) illustrates the elevation and plan of the portable pre-cooling unit used for the experimental work. The main frame of the unit was constructed of $(4 \times 4 \mathrm{~cm})$ iron angles with dimensions of $215.6 \mathrm{~cm}$ long, $62 \mathrm{~cm}$ wide and $120 \mathrm{~cm}$ high. The main frame was fixed on four wheels of $25 \mathrm{~cm}$ diameter. The cooling chamber, refrigerating system and humidifying system were assembled on the main frame. The cooling chamber shown in Fig.(2) consisted of an angles iron frame covered with double galvanized steel sheets $(1 \mathrm{~mm}$ thick) filled with $7.7 \mathrm{~cm}$ thick polyurethane foam at an injected density of $38-40 \mathrm{~kg} / \mathrm{m}^{3}$. The dimensions of the chamber were $170.6 \mathrm{~cm}$ long, $72 \mathrm{~cm}$ wide and $120 \mathrm{~cm}$ high. Two doors were fixed on the front side of the chamber frame. The first door was used for charging and discharging the product, while the second door was used for accommodation of the refrigeration and the control units. A rubber seal was fixed on the edges of the cooling chamber door to prevent leakage of cold air. A humidifying unit was also used to increase the air relative humidity inside the cooling chamber by misting water inside the chamber under controlled condition. For accommodation of fruit packages a cooling bed consists of three stands made of steel angle $(3 \times 3 \mathrm{~cm})$ with dimension of $52 \mathrm{~cm}$ long, $35 \mathrm{~cm}$ wide and $80 \mathrm{~cm}$ high was installed inside the cooling chamber. The product package consists of nine boxes with capacity of 3.5 and $2.75 \mathrm{~kg}$ for large and medium volume peach fruits, respectively. The tested packages (rectangular shape boxes) were made of wood with dimensions of $50 \mathrm{~cm}$ long, $33 \mathrm{~cm}$ wide and $10 \mathrm{~cm}$ high. The longer sides of each box (facing the air moving direction) were perforated at vents percentage of 4,6 and $8 \%$ of the total surface area of each box.

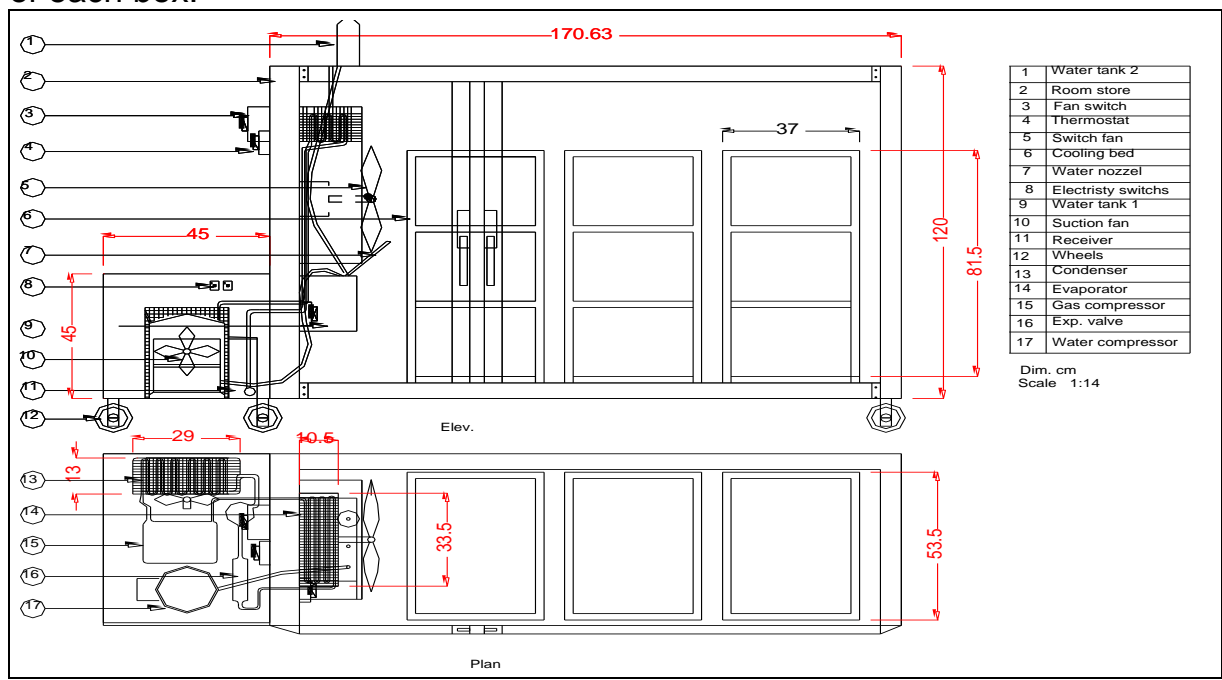

Fig. (1): Elevation and plan of the portable pre-cooling unit 


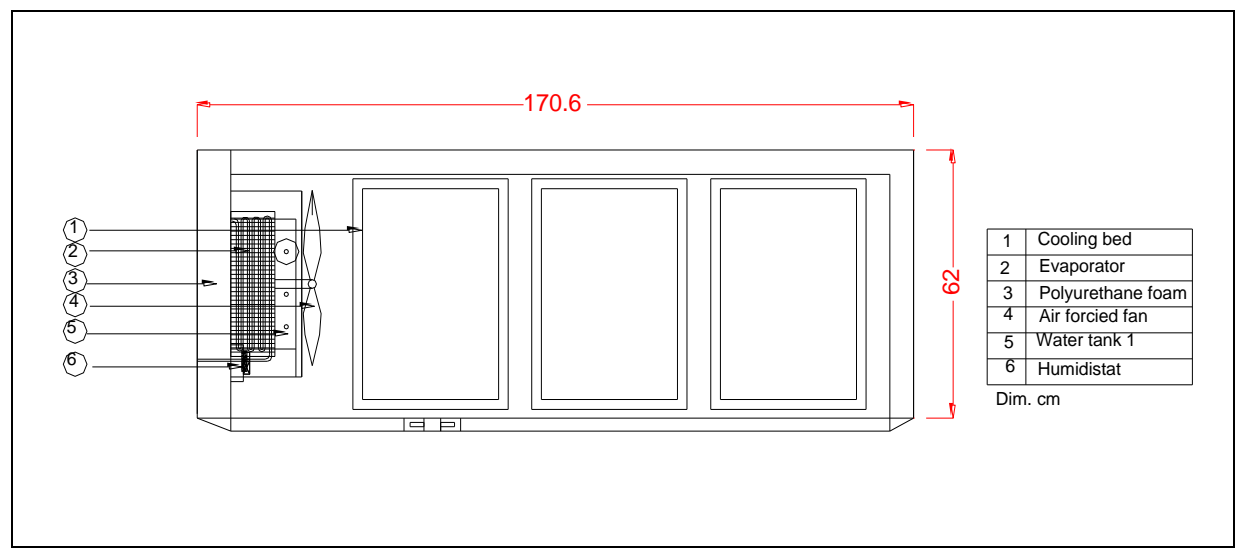

Fig. (2): Schematic diagram of the cooling chamber.

\section{Experimental Treatments:}

The laboratory experiments were conducted at three levels of air temperature $\left(4,7\right.$ and $\left.10^{\circ} \mathrm{C}\right)$, three levels of air velocity $(3.7,4.8$ and $5.4 \mathrm{~m} / \mathrm{s})$, three levels of packages vents percentage $(4,6$ and $8 \%)$ and two volumes of peach fruits (medium and large).

\section{Experimental Measurements and Test Procedure:}

During the course of experimental work, several measurements were conducted either directly or indirectly depending on the natural of the measurement itself. The measurements included fruit core temperature, medium air temperature, air velocity, relative humidity, product weight, fruit firmness, and fruit decay.

Freshly harvested peach samples var. (Palade) at maturity stage were collected from private farm in El-Ruid area-Kafr El-Sheikh Governorate. Prior to each experimental run, the fruits sample was sorted to select the sound fruit with similar volume. The selected fruits of the required volume were loaded inside the packages boxes and left inside the laboratory to attain the ambient temperature. The temperature of the air cooler was adjusted to the required level using a precious thermostat. This was checked using a set of thermocouples suspended at front of the fan and at different locations of the cooling chamber. Further more the desired air velocity was adjusted using the air velocity control switch to obtain the required air velocity. The relative humidity was also adjusted at $90 \pm 2 \%$ using the humidistat to avoid water losses from the product. The cooling unit was operated without any product load far about $30 \mathrm{~min}$. to attain stable operation condition then, the product was loaded into the cooling chamber at nine packages arranged in equal number of sets (three packages at top-middle and bottom) of the fruit accommodation studs. At each level the three packages were also arranged at front, middle and end of the accommodation studs. The packing method of each package was done considering the possible similarity of fruit volume and weight. Eighteen thermocouples were used to measure the product temperature using the universal digital measuring system model (KAYE, DIG4). Two thermocouples were inserted in quarter diameter of two randomly selected fruits of each package. The average temperature of each group 
were taken and the experiment stopped when the average temperature of the three group was decreased to approximately $12.5 \%$ of the difference between the initial temperature of the fruits and the temperature of the cooling air (seven-eighth cooling time).

\section{Estimating half and seven-eighth cooling times:}

As shown in Fig. (3) regression analyses were carried out on the dimensionless temperature data in the exponential form (temperature ratio) to determine the half and seven-eighth cooling time using the following equation:

$$
\theta=J \exp (-C t)
$$

Where:

Lag factor $(\mathrm{J})$ is the intercept of the straight-line asymptote at time 0 Cooling coefficient $(C)$ is the slope of the line resulting from a plot of the natural log of the temperature ratio versus time (inverse time). From the regression analyses the lag factors $(\mathrm{J})$ and cooling coefficients $(\mathrm{C})$ were determined and hence, the half $(\mathrm{H})$ and seven-eighth $(\mathrm{S})$ cooling times were calculated by means of the equations.

$$
\begin{aligned}
& H=\frac{\ln 2 J}{C} \\
& S=\frac{\ln 8 J}{C} .
\end{aligned}
$$

\section{Calculation Of The Refrigeration Load:}

The actual refrigeration load of the developed pre-cooling unit was calculated using the following formulas (Debney et al., 1980)

$$
P=\frac{W\left(T_{i}-T_{a}\right) x 1.28}{S}
$$

Where: $\mathrm{P}=$ product refrigeration load $(\mathrm{w})$

$\mathrm{W}=$ product weight $(\mathrm{Kg})$

$\mathrm{S}=$ seven-eighth cooling time, $\mathrm{h}$

$\mathrm{Ti}=$ initial temperature of product to be cold, ${ }^{\circ} \mathrm{C}$

$\mathrm{Ta}=$ temperature of air cooling medium, ${ }^{\circ} \mathrm{C}$

As stated by (Thompson et al., 1998) and for a reasonably airtight and well insulated cooler used for the fast cooling of fresh produce, more than $80 \%$ of the total refrigeration capacity is available for the cooling of the product. The remaining $20 \%$ is used to cope with extraneous heat load. The total refrigeration load required may be estimated as follows;

$$
\mathrm{Pt}=\mathrm{Px} 1.25 \text {. }
$$

Where: $\mathrm{Pt}=$ total refrigeration load. 
EI-kholy, M. M. et al.

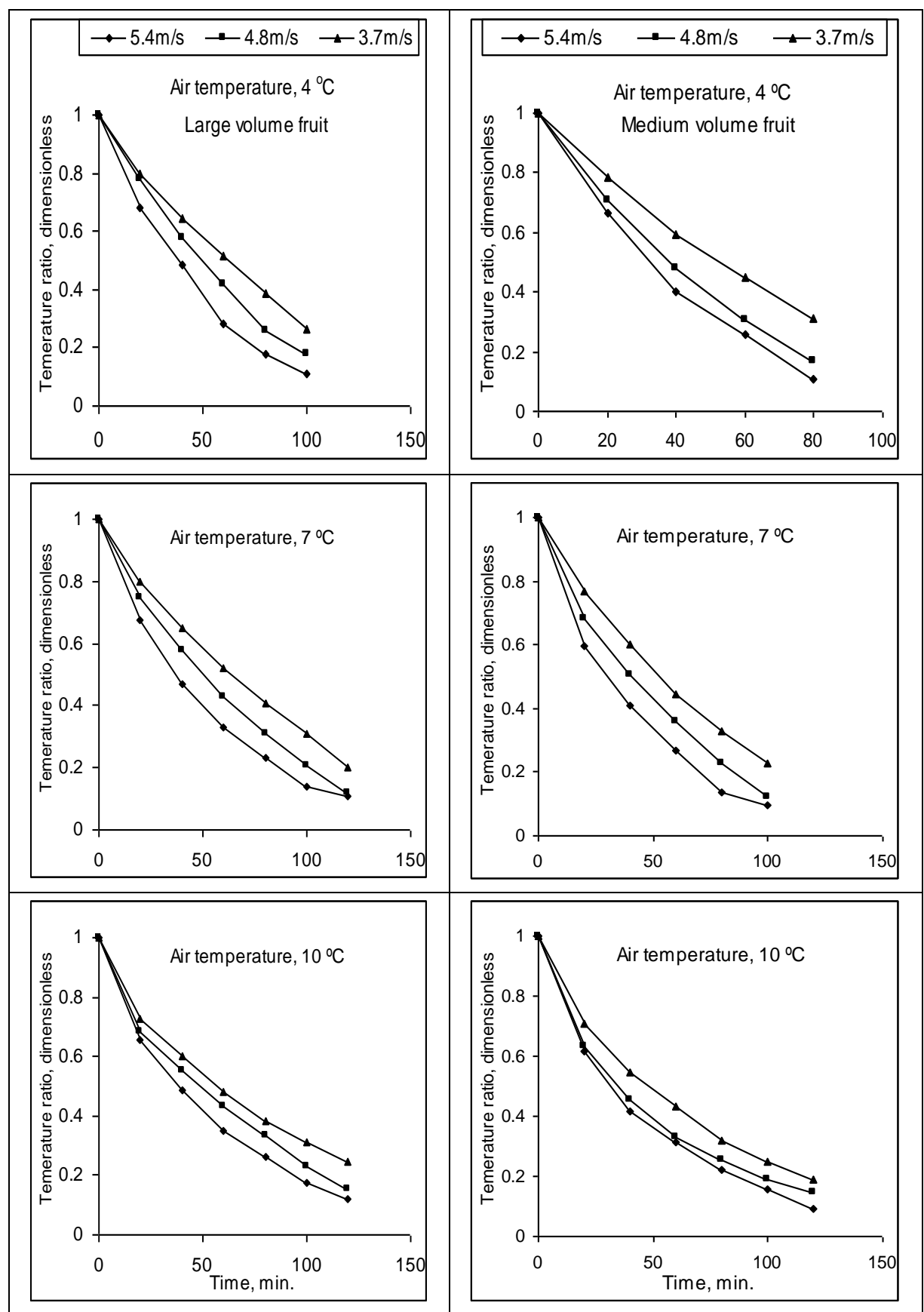

Fig. (3): Average temperature ratio of peach fruits as related to cooling time for different air cooling temperature and air velocity at packages vents percentage of $8 \%$. 


\section{Storage Experiments:}

Two different sets of pre-cooled and none pre-cooled products of peach fruits were stored at $4{ }^{\circ} \mathrm{C}$ and $90 \% \mathrm{RH}$. Two similar sets were also stored at room temperature of $27{ }^{\circ} \mathrm{C}( \pm 3)$ and $59 \%( \pm 2) \mathrm{RH}$ as control. Sample of each treatment was taken every two days for the cooled storage treatment and every one day for the ambient storage treatment. Quality evaluations of samples including fruit firmness using Effige pentrometer with $8 \mathrm{~mm}$ probe, weight losses of the product using a digital electric balance with a maximum capacity of $5 \mathrm{~kg}$ and accuracy of $0.1 \mathrm{~g}$, and fruit decay visual inspection were conducted.

\section{RESULTS AND DISCUSSION}

\section{Fruits Temperature:}

Figures (4) and (5) illustrate the fruit temperature as related to the cooling time of peach at the minimum and maximum cooling air temperature different air velocity, percentage of packages vents and volume of fruits (large and medium). The obtained data represent the average temperature of the packages located at front, middle and end positions from the forced air direction and the average of thermocouples reading of top, middle and bottom levels on the packages stands. The figures show that the temperature of the fruits at the end position of the cooling chamber was always higher than that of the middle and front as well. This means that the cooling rate became very slow at the end of the cooling chamber. In general, the cooling time of fruits was varied and depends upon fruit volume, cooling air temperature, air velocity and percentage of vents.

The Cooling Coefficient $(\mathrm{C})$ and Lag Factor $(\mathrm{J})$ :

Table (1) illustrates the value of the coefficient of determination $\left(R^{2}\right)$; lag factor (J), cooling coefficient (C) and standard error (S.E) for peach fruits.

As can be seen from the table the coefficient of determination $\left(R^{2}\right)$ ranged from 0.9682 to 0.9991 and the lag factor $(J)$ ranged from 0.8937 to 1.1698. As can also be seen from table (1) and Fig. (6) the values of cooling coefficient $(\mathrm{C})$ increased with the increase of air velocity $(\mathrm{V})$, increase of packages vents percentage, decreasing the fruit volume and decreasing the cooling air temperature.

Half and Seven-eighth Cooling Times:

In general, both the half and the seven-eighth cooling times of peach fruits decreased with the increase of air velocity and the increase of packages vents percentage while, they were increased with the increase of cooling temperature and increase of product volume. Table (2) presents the half and seven-eighth cooling times of peach fruits cooled at different levels of air temperature, air velocity, and packages vents percentage. From the data presented in table (2), for large volume peach fruits decreasing the cooling air temperature from 10 to $4^{\circ} \mathrm{C}$ decreased the seven-eighth cooling times from 171.53 to $139.77,138.8$ to 119.5 and 120.6 to $96.51 \mathrm{~min}$. for the maximum packages vents percentage of $8 \%$ and air velocity of $3.7,4.8$ and $5.4 \mathrm{~m} / \mathrm{s}$, respectively. The corresponding reduction ranges of seven-eighth cooling time for the medium volume fruit were 149.45 to $125.78,126.9$ to 92.16 and 
107.5 to $80.5 \mathrm{~min}$, respectively. The calculated half cooling time at similar levels of air temperature decreased from 56.96 to $53.12,46.4$ to 43.71 and 39.03 to $34.06 \mathrm{~min}$. for large volume fruits and from 48.26 to $46.57,37.46$ to 34.15 and 34.13 to $29.3 \mathrm{~min}$. for medium volume fruits. Similar trends were observed for packages vents of 4 and $6 \%$.

Table (1): The lag factor (J) and cooling coefficient (C) of peach fruits cooled under different experimental variables.

\begin{tabular}{|c|c|c|c|c|c|c|c|c|c|c|c|c|c|c|}
\hline \multirow{3}{*}{ 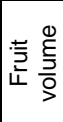 } & \multirow{3}{*}{$\begin{array}{l}\stackrel{\circ}{0} \\
\stackrel{\infty}{C} \\
\stackrel{0}{\infty}\end{array}$} & \multirow{3}{*}{$\begin{array}{l}0 \\
\stackrel{0}{E} \\
\frac{0}{0} \\
\bullet\end{array}$} & \multicolumn{12}{|c|}{ Air velocity, $\mathrm{m} / \mathrm{s}$} \\
\hline & & & \multicolumn{4}{|c|}{5.4} & \multicolumn{4}{|c|}{4.8} & \multicolumn{4}{|c|}{3.7} \\
\hline & & & J & $\begin{array}{c}\mathrm{C}, \\
\text { min. }^{-1}\end{array}$ & $\mathrm{R}^{2}$ & S.E & J & $\begin{array}{c}\mathrm{C}, \\
\mathrm{min}^{-1}\end{array}$ & $\mathrm{R}^{2}$ & S.E & J & $\begin{array}{c}\mathrm{C}, \\
\text { min. }^{-1}\end{array}$ & $\mathrm{R}^{2}$ & S.E \\
\hline \multirow{9}{*}{ 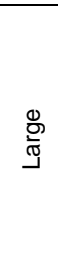 } & \multirow{3}{*}{8} & 4 & 1.0650 & 0.0222 & 0.9953 & 6.35 & 1.1128 & 0.0183 & 0.9907 & 8.36 & 1.1698 & 0.0160 & 0.9709 & 14.63 \\
\hline & & 7 & 1.0003 & 0.0189 & 0.9966 & 5.22 & 1.0899 & 0.0171 & 0.9833 & 10.54 & 1.1264 & 0.0144 & 0.9685 & 13.7 \\
\hline & & 10 & 0.9708 & 0.0170 & 0.9972 & 4.25 & 1.0025 & 0.0150 & 0.9930 & 5.58 & 0.9961 & 0.0121 & 0.9933 & 5.78 \\
\hline & \multirow{3}{*}{6} & 4 & 1.0290 & 0.0172 & 0.9913 & 7.60 & 1.0252 & 0.0150 & 0.9978 & 4.33 & 1.0873 & 0.0142 & 0.9971 & 4.47 \\
\hline & & 7 & 1.0214 & 0.0161 & 0.9914 & 7.94 & 1.0676 & 0.0148 & 0.9936 & 6.78 & 1.1010 & 0.0125 & 0.9750 & 11.73 \\
\hline & & 10 & 1.0209 & 0.0151 & 0.9991 & 2.38 & 1.0652 & 0.0128 & 0.9943 & 5.66 & 1.0293 & 0.0114 & 0.9982 & 3.11 \\
\hline & \multirow{3}{*}{4} & 4 & 1.0326 & 0.0140 & 0.9835 & 9.63 & 1.0856 & 0.0124 & 0.9 & 12.92 & 1.05 & 0.0107 & 0.9778 & 10.32 \\
\hline & & 7 & 1.0175 & 0.0136 & 0.9973 & 4.14 & 1.0853 & 0.0120 & 0.9682 & 12.71 & 1.0663 & 0.0104 & 0.9669 & 12.41 \\
\hline & & 10 & 0.9719 & 0.0134 & 0.9932 & 4.18 & 1.0660 & 0.0117 & 0.9950 & 5.3 & 1.0562 & 0.0099 & 0.9943 & 5.22 \\
\hline \multicolumn{3}{|c|}{ Mean } & 1.0144 & 0.0164 & 0.9939 & 5.74 & 1.0667 & 0.0143 & 0.9872 & 7.810 & 1.0764 & 0.0124 & 0.9824 & 9.0411 \\
\hline \multirow{9}{*}{ 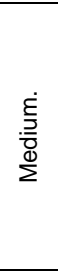 } & \multirow{3}{*}{8} & 4 & 1.1066 & 0.0271 & 0.9752 & 15.74 & 1.1310 & 0.0239 & 0.9857 & 12.05 & 1.1295 & 0.0175 & 0.9811 & 11.48 \\
\hline & & 7 & 1.0089 & 0.0238 & 0.9948 & 7.18 & 1.0682 & 0.0202 & 0.9809 & 11.80 & 1.1034 & 0.0165 & 0.9755 & 12.40 \\
\hline & & 10 & 0.95 & 0.0189 & 0.99 & 7.95 & 0.8937 & 0.0155 & 0.95 & 6.38 & 0.9 & 0.0137 & 0.9991 & 2.39 \\
\hline & \multirow{3}{*}{6} & 4 & 0.9502 & 0.0186 & 0.9977 & 4.20 & 0.9942 & 0.0165 & 0.9930 & 2.25 & 1.0396 & 0.0142 & 0.9924 & 6.60 \\
\hline & & 7 & 0.9719 & 0.0182 & 0.9932 & 7.15 & 0.9722 & 0.0156 & 0.9 & 7.88 & 1.0 & 0.0140 & $0.9 \mathrm{~s}$ & 7.54 \\
\hline & & 10 & 0.9375 & 0.0172 & 0.9968 & 4.63 & 0.9761 & 0.0145 & 0.9988 & 2.62 & & 0.0137 & 0.9875 & 8.99 \\
\hline & \multirow{3}{*}{4} & 4 & 0.9712 & 0.0174 & 0.9994 & 1.20 & 1.0493 & 0.0161 & 0.9960 & 5.42 & 1.0596 & 0.0135 & 0.9952 & 5.47 \\
\hline & & 7 & 1.0707 & 0.0161 & 0.9960 & 5.42 & 1.1380 & 0.0149 & 0.9738 & 12.90 & 1.1362 & 0.0127 & 0.9734 & 12.29 \\
\hline & & 10 & 1.0671 & 0.0159 & 0.9952 & 5.86 & 1.0950 & 0.0140 & 0.9912 & 8.99 & 1.1734 & 0.0125 & 0.9772 & 12.27 \\
\hline \multicolumn{3}{|c|}{ Mean } & 1.0047 & 0.0195 & 0.9946 & 6.25 & 1.0353 & 0.0168 & 0.9894 & 7.810 & 1.0855 & 0.0122 & 0.9858 & 8.82 \\
\hline
\end{tabular}

Table (2): The half and seven-eighth cooling times of peach fruits for the average values of front, middle and end packages.

\begin{tabular}{|c|c|c|c|c|c|c|c|c|}
\hline \multirow{3}{*}{$\begin{array}{l}\text { Fruit } \\
\text { volume }\end{array}$} & \multirow{3}{*}{ Vents, \% } & \multirow{3}{*}{ Temp., C } & \multicolumn{6}{|c|}{ Air velocity, $\mathrm{m} / \mathrm{s}$} \\
\hline & & & \multicolumn{2}{|c|}{5.4} & \multicolumn{2}{|c|}{4.8} & \multicolumn{2}{|c|}{3.7} \\
\hline & & & $\mathrm{H}$, min. & $\mathrm{S}$, min. & $\mathrm{H}, \mathrm{min}$. & $\mathrm{S}$, min. & $\mathrm{H}$, min. & $\mathrm{S}$, min. \\
\hline \multirow{9}{*}{$\begin{array}{l}\stackrel{D}{0} \\
\text { త్ర }\end{array}$} & \multirow{3}{*}{8} & 4 & 34.06 & 96.51 & 43.717 & 119.5 & 53.12 & 139.77 \\
\hline & & 7 & 36.69 & 110 & 45.569 & 126.6 & 56.4 & 152.67 \\
\hline & & 10 & 39.03 & 120.6 & 46.376 & 138.8 & 56.96 & 171.53 \\
\hline & \multirow{3}{*}{6} & 4 & 41.96 & 122.6 & 47.869 & 140.3 & 54.71 & 152.33 \\
\hline & & 7 & 44.37 & 130.5 & 51.254 & 144.9 & 63.15 & 174.05 \\
\hline & & 10 & 47.27 & 139.1 & 59.087 & 167.4 & 63.34 & 184.94 \\
\hline & \multirow{3}{*}{4} & 4 & 51.8 & 150.8 & 62.523 & 174.3 & 69.84 & 199.4 \\
\hline & & 7 & 52.24 & 154.2 & 64.584 & 180.1 & 72.82 & 206.12 \\
\hline & & 10 & 53 & 155.5 & 64.706 & 183.2 & 75.54 & 215.57 \\
\hline \multirow{9}{*}{ 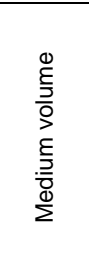 } & \multirow{3}{*}{8} & 4 & 29.3 & 80.5 & 34.153 & 92.16 & 46.57 & 125.78 \\
\hline & & 7 & 29.5 & 87.74 & 37.58 & 106.2 & 47.97 & 131.99 \\
\hline & & 10 & 34.13 & 107.5 & 37.469 & 126.9 & 48.26 & 149.45 \\
\hline & \multirow{3}{*}{6} & 4 & 34.52 & 109.1 & 41.656 & 125.7 & 51.55 & 149.17 \\
\hline & & 7 & 36.52 & 112.7 & 42.625 & 131.5 & 54.88 & 153.9 \\
\hline & & 10 & 36.55 & 117.1 & 46.135 & 141.7 & 56.35 & 157.54 \\
\hline & \multirow{3}{*}{4} & 4 & 38.16 & 117.8 & 46.042 & 132.1 & 55.63 & 158.32 \\
\hline & & 7 & 47.3 & 133.4 & 55.196 & 148.2 & 64.63 & 173.79 \\
\hline & & 10 & 47.68 & 134.9 & 55.993 & 155 & 68.24 & 179.15 \\
\hline
\end{tabular}


J. of Soil Sciences and Agricultural Engineering, Vol. 1 (1), January, 2010
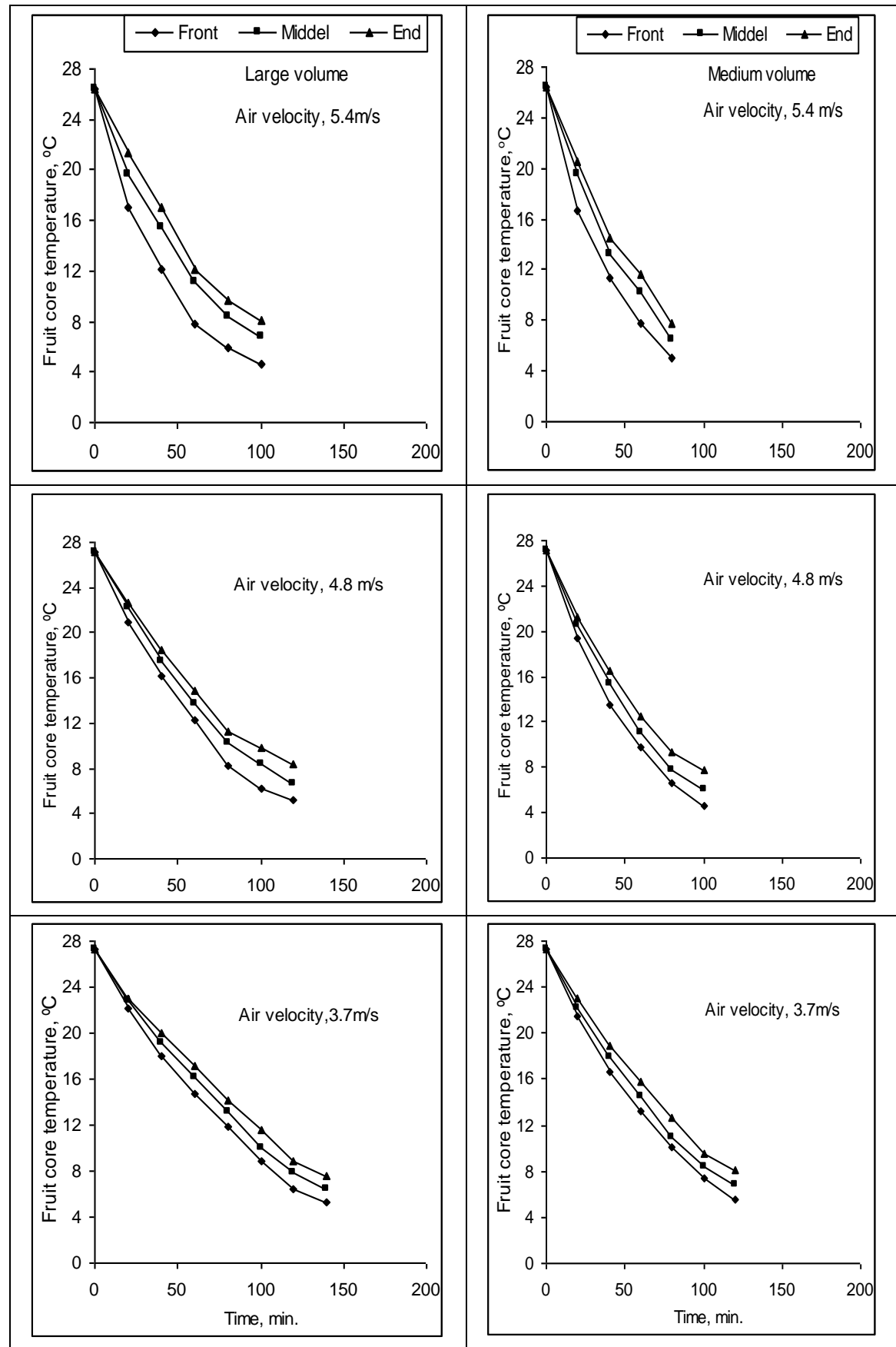

Fig. (4): Average core temperature of peach fruits as related to cooling time for the minimum air cooling temperature of 4 으 $\mathrm{C}$ and packages vents percentage of $8 \%$. 
El-kholy, M. M. et al.
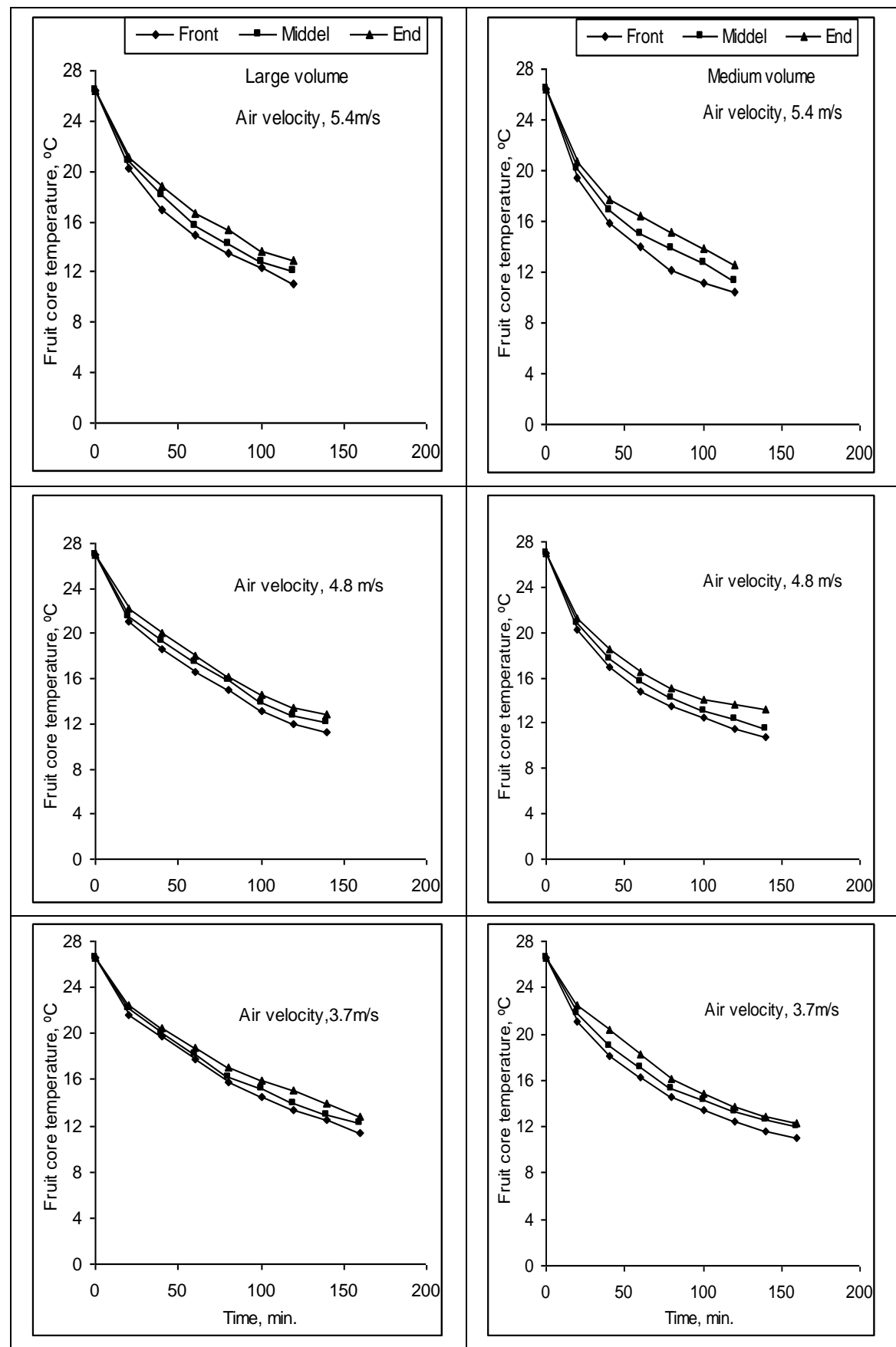

Fig. (5): Average core temperature of peach fruits as related to cooling time for the maximum air cooling temperature of $10 \stackrel{\circ}{ } \mathrm{C}$ and packages vents percentage of $8 \%$. 


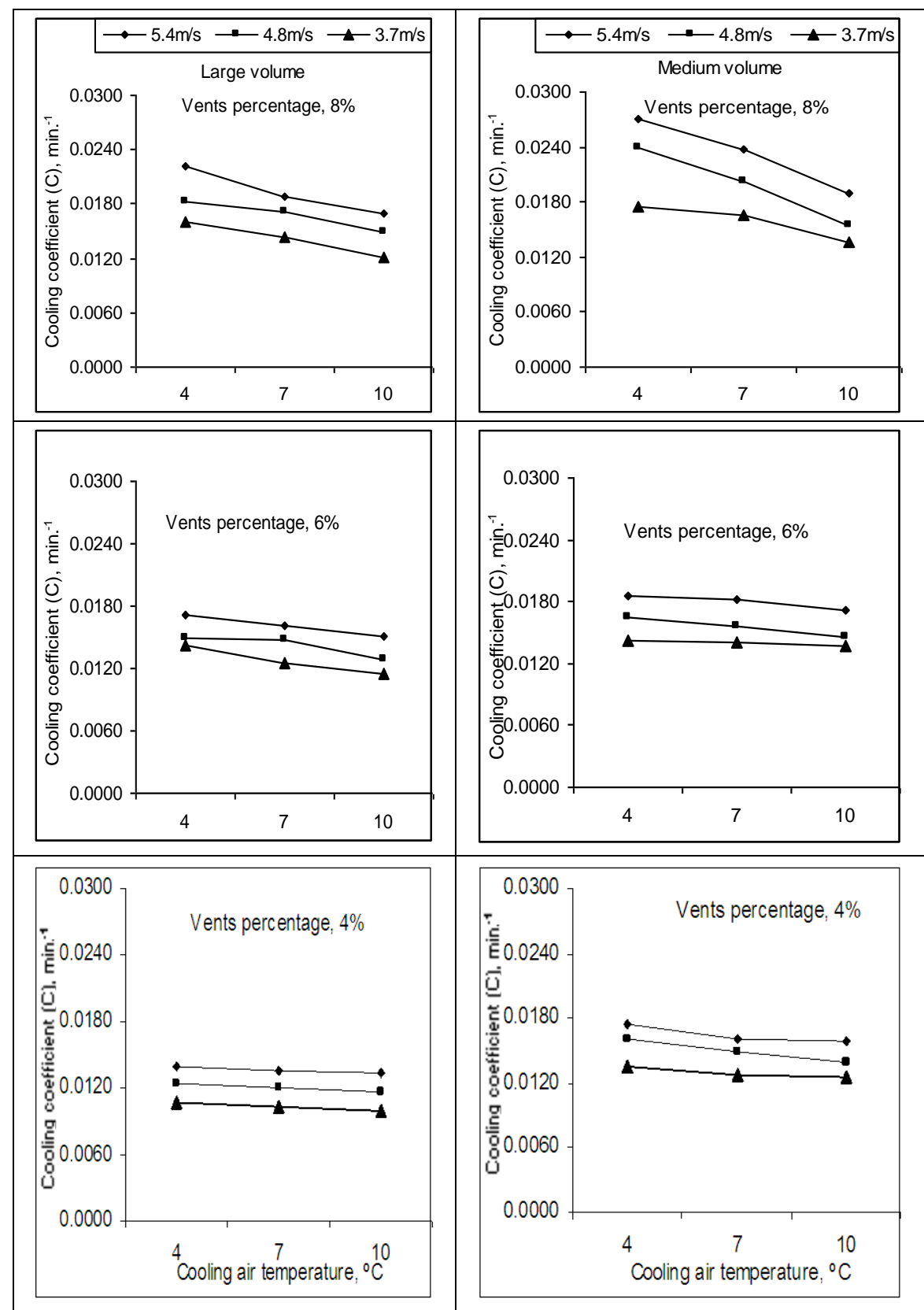

Fig. (6): Effect of cooling air temperature on cooling coefficient (C) at different levels of air velocity, packages vents percentage and volume on peach fruits. 


\section{Refrigeration Load:}

The average estimated refrigeration load $\left(P_{t}\right)$ at different air velocity, air temperature, packages vents percentage and volumes of peach fruits are tabulated in Table (3). Considering the capacity of packages equal about 3.5 and $2.75 \mathrm{~kg} \pm 0.16 \mathrm{~kg}$ for large and medium volume peach fruits. The refrigeration load $\left(P_{t}\right)$ decreased with the increase of cooling temperature, decrease of air velocity and decrease of vent percentage. As can be seen from the table, decreasing the cooling air temperature tends to increase the total refrigeration load at different levels of air velocity and vents percentage. From the obtained data it was clear that, for the large volume fruits, decreasing the air temperature from 10 to $4^{\circ} \mathrm{C}$ tends to increase the total refrigeration load from 411.3 to $701.9,370.4$ to 584.7 and 292.6 to $504.1 \mathrm{~W}$ at air velocity of $5.4,4.8$ and $3.7 \mathrm{~m} / \mathrm{s}$, respectively and packages vents percentage of $8 \%$. The corresponding values for the medium volume fruits ranged from 362.6 to $661.4,318.3$ to 595.6 and 263.9 to $440.1 \mathrm{~W}$, respectively. This trend may be due to increasing the motor operating time with the decrease of cooling air temperature, increase of air velocity and increase of vents percentage.

Table (3): The initial temperature $\left(T_{i}\right)$, estimated refrigeration capacity $(P)$ and total refrigeration load $\left(P_{t}\right)$ for peach fruits.

\begin{tabular}{|c|c|c|c|c|c|c|c|c|c|c|c|}
\hline \multirow{3}{*}{$\begin{array}{l}\text { Fruit } \\
\text { volume }\end{array}$} & \multirow{3}{*}{$\begin{array}{c}\text { Vents, } \\
\%\end{array}$} & \multirow{3}{*}{$\mathrm{T}_{\mathrm{a}},{ }^{\circ} \mathrm{C}$} & \multicolumn{9}{|c|}{ Air velocity, m/s } \\
\hline & & & \multicolumn{3}{|c|}{5.4} & \multicolumn{3}{|c|}{4.8} & \multicolumn{3}{|c|}{3.7} \\
\hline & & & $\mathrm{T}_{\mathrm{i},}{ }^{\circ} \mathrm{C}$ & $\mathrm{P}, \mathrm{W}$ & $\mathrm{Pt}, \mathrm{W}$ & $\mathrm{T}_{\mathrm{i}},{ }^{\circ} \mathrm{C}$ & $\mathrm{P}, \mathrm{W}$ & $\mathrm{Pt}, \mathrm{W}$ & $\mathrm{T}_{\mathrm{i}},{ }^{\circ} \mathrm{C}$ & $\mathrm{P}, \mathrm{W}$ & $\mathrm{Pt}, \mathrm{W}$ \\
\hline \multirow{9}{*}{ ర్ల } & \multirow{3}{*}{8} & 4 & 26.4 & 561.5 & 701.9 & 27.1 & 467.8 & 584.7 & 27.3 & 403.3 & 504.1 \\
\hline & & 7 & 27.3 & 446.3 & 557.9 & 26.5 & 372.5 & 465.6 & 25.7 & 296.3 & 370.4 \\
\hline & & 10 & 26.4 & 329 & 411.3 & 27.0 & 296.3 & 370.4 & 26.6 & 234.1 & 292.6 \\
\hline & \multirow{3}{*}{6} & 4 & 24.5 & 404.6 & 505.8 & 25.2 & 365.6 & 457 & 25.5 & 341.4 & 426.8 \\
\hline & & 7 & 24.9 & 331.9 & 414.9 & 25.5 & 308.8 & 386 & 25.5 & 257.1 & 321.4 \\
\hline & & 10 & 25.7 & 273.1 & 341.4 & 26.0 & 231.2 & 289 & 26.5 & 215.8 & 269.8 \\
\hline & \multirow{3}{*}{4} & 4 & 26.4 & 359.3 & 449.1 & 26.0 & 305.3 & 381.6 & 26.0 & 266.9 & 333.6 \\
\hline & & 7 & 26.5 & 306 & 382.5 & 26.1 & 256.5 & 320.7 & 26.5 & 228.9 & 286.1 \\
\hline & & 10 & 27.0 & 268.7 & 335.9 & 26.5 & 217.9 & 272.4 & 25.7 & 176.2 & 220.2 \\
\hline \multirow{9}{*}{$\begin{array}{l}\frac{E}{J} \\
\frac{\bar{g}}{\mathrm{~g}} \\
\sum\end{array}$} & \multirow{3}{*}{8} & 4 & 26.4 & 529.1 & 661.4 & 27.1 & 476.5 & 595.6 & 27.3 & 352.1 & 440.1 \\
\hline & & 7 & 27.3 & 439.8 & 549.7 & 26.5 & 349 & 436.2 & 25.7 & 269.3 & 336.6 \\
\hline & & 10 & 26.4 & 290 & 362.6 & 27.0 & 254.6 & 318.3 & 26.6 & 211.1 & 263.9 \\
\hline & \multirow{3}{*}{6} & 4 & 25.0 & 366 & 457.5 & 25.3 & 322.2 & 402.7 & 25.5 & 274 & 342.4 \\
\hline & & 7 & 25.0 & 303.6 & 379.5 & 25.4 & 266 & 332.5 & 23.4 & 202.6 & 253.2 \\
\hline & & 10 & 25.8 & 256.4 & 320.5 & 23.6 & 182.4 & 228 & 24.0 & 168.9 & 211.1 \\
\hline & \multirow{3}{*}{4} & 4 & 25.5 & 346.8 & 433.5 & 26.0 & 316.4 & 395.6 & 26.5 & 270.1 & 337.7 \\
\hline & & 7 & 26.0 & 270.7 & 338.4 & 26.3 & 247.5 & 309.4 & 26.0 & 207.8 & 259.8 \\
\hline & & 10 & 26.6 & 234 & 292.4 & 27.0 & 208.5 & 260.6 & 27.0 & 180.4 & 225.5 \\
\hline
\end{tabular}

\section{Quality Evaluation Tests During Storage Process:}

Quality evaluation tests included measurements of fruit weight loss, fruit defects and fruit firmness were conducted every two days for the cold storage treatment and every one day for the room storage method. The obtained results could be presented as follows:

\section{Weight Losses Of Peach Fruits:}

A weight loss occurs in fruits due to respiration and by moisture transpiration due to the potential loss in its water content. As shown in tables ( 4 and 5 ), as the cooled storage period elongated to 14 days the fruits weight losses increased from 0 to $3.2 \%$ and from 0 to $2.9 \%$ for large and medium volume pre-cooled samples, respectively. While the corresponding values for 
the none pre-cooled samples ranged from 0 to $3.9 \%$ and from 0 to $3.5 \%$ for large and medium volume fruits, respectively. On the other hand when the room storage period was elongated to two days only nearly similar weight losses were observed for large and medium volume pre-cooled fruits.

\section{Fruit Defects:}

The defects like discoloration, decay, pitting and softening appeared after 12 and 8 days of cooled storage for the pre-cooled and none pre-cooled samples, respectively. While the defects appeared after 3days only for the pre-cooled and none pre-cooled samples stored in room storage. This means that, increasing water loss for fruits stored in room storage damaged the flesh structure and the cell membrane resulting in more pathological and physiological changes leading to the increased rate of various fungi invasion as mentioned by (Kalbasi-Ashtari, . 2004).

\section{Fruit firmness}

The firmness of peach fruits gradually decreased with the increasing of storage time in both cooled and room storage methods. As shown in tables ( 4 and 5), when the cooled storage period was elongated to 14 days the precooled fruit firmness decreased from 19.8 to $6.9 \mathrm{~kg} / \mathrm{cm}^{2}$ and from 20.1 to 9.4 $\mathrm{kg} / \mathrm{cm}^{2}$ for large and medium fruit volumes, respectively. While the corresponding values for the none pre-cooled sample ranged from 19.8 to 5.5 $\mathrm{kg} / \mathrm{cm}^{2}$ and from 20.1 to $6.4 \mathrm{~kg} / \mathrm{cm}^{2}$ for large and medium fruits volumes, respectively. On the other hand for the pre-cooled samples when the room storage period was elongated to 7 days only the fruit firmness decreased from 19.8 to $2.2 \mathrm{~kg} / \mathrm{cm}^{2}$ and from 20.1 to $2.7 \mathrm{~kg} / \mathrm{cm}^{2}$ for large and medium fruit volumes, respectively. The corresponding value for the none pre-cooled sample were from 19.8 to $1.5 \mathrm{~kg} / \mathrm{cm}^{2}$ and from 20.1 to $2.2 \mathrm{~kg} / \mathrm{cm}^{2}$ after 6 days. Increasing the fruit firmness for the cooled storage condition compared to the room storage could be attributed to the reduction of respiration rate and the decrease in water loss which resulted in retention of firmness during storage. The ambient storage methods showed dramatic reduction of fruit firmness as presented in tables (4) and (5).

Table (4): Effect of pre-cooling treatment of peach fruits on fruit weight losses (WL, \%), defects (\%), and firmness $\left(\mathrm{Kg} / \mathrm{cm}^{2}\right)$ during cold storage.

\begin{tabular}{|c|c|c|c|c|c|c|c|c|c|c|}
\hline \multirow{2}{*}{$\begin{array}{l}\text { Measured } \\
\text { parameters }\end{array}$} & \multirow{2}{*}{ Treatments } & \multirow{2}{*}{ Fruit volumes } & \multicolumn{8}{|c|}{ Stored period, day } \\
\hline & & & 0 & 2 & 4 & 6 & 8 & 10 & 12 & 14 \\
\hline \multirow{4}{*}{$\begin{array}{c}\text { Weight losses, } \\
\%\end{array}$} & \multirow{2}{*}{ Pre-cooled } & Large & 0 & 0.28 & 0.59 & 1.1 & 1.8 & 2.5 & 2.6 & 3.2 \\
\hline & & Medium & 0 & 0.2 & 0.55 & 0.98 & 1.6 & 2.2 & 2.7 & 2.9 \\
\hline & \multirow{2}{*}{$\begin{array}{c}\text { None pre- } \\
\text { cooled }\end{array}$} & Large & 0 & 0.9 & 1.2 & 2.4 & 2.8 & 3.2 & 3.5 & 3.9 \\
\hline & & Medium & 0 & 0.8 & 1.1 & 2.1 & 2.6 & 3 & 3.3 & 3.5 \\
\hline \multirow{4}{*}{ Defects,\% } & \multirow{2}{*}{ Pre-cooled } & Large & - & - & - & - & - & - & 6.2 & 10.5 \\
\hline & & Medium & - & - & - & - & - & - & 2.3 & 8.4 \\
\hline & \multirow{2}{*}{$\begin{array}{l}\text { None pre- } \\
\text { cooled. }\end{array}$} & Large & - & - & - & - & 9.6 & 10.8 & 15.7 & 20.7 \\
\hline & & Medium & - & - & - & - & 6.3 & 7.4 & 13.5 & 17.5 \\
\hline \multirow{4}{*}{$\begin{array}{l}\text { Firmness, } \\
\mathrm{kg} / \mathrm{cm}^{2}\end{array}$} & \multirow{2}{*}{ Pre-cooled } & Large & 19.8 & 18.1 & 16.5 & 14.8 & 12.9 & 11.1 & 8.7 & 6.9 \\
\hline & & Medium & 20.1 & 19.5 & 18 & 16.1 & 14.3 & 12.5 & 11.1 & 9.4 \\
\hline & \multirow{2}{*}{$\begin{array}{l}\text { None pre- } \\
\text { cooled }\end{array}$} & Large & 19.8 & 17.1 & 15.4 & 13.5 & 11.4 & 9.2 & 7.4 & 5.5 \\
\hline & & Medium & 20.1 & 18.0 & 15.9 & 14.2 & 12.5 & 11.0 & 8.1 & 6.4 \\
\hline
\end{tabular}


EI-kholy, M. M. et al.

Table (5): Effect of pre-cooling treatment of peach fruits on fruit weight losses (WL, \%), defects (\%), and firmness $\left(\mathrm{Kg} / \mathrm{cm}^{2}\right)$ during room storage.

\begin{tabular}{|c|c|c|c|c|c|c|c|c|c|c|}
\hline \multirow{2}{*}{$\begin{array}{l}\text { Measured } \\
\text { parameters }\end{array}$} & \multirow{2}{*}{ Treatments } & \multirow{2}{*}{$\begin{array}{c}\begin{array}{c}\text { Fruit } \\
\text { volumes }\end{array} \\
\end{array}$} & \multicolumn{8}{|c|}{ Stored period, day } \\
\hline & & & 0 & 1 & 2 & 3 & 4 & 5 & 6 & 7 \\
\hline \multirow{4}{*}{$\begin{array}{c}\text { Weight losses, } \\
\%\end{array}$} & \multirow{2}{*}{ Pre-cooled } & Large & 0 & 2 & 3.2 & 4.5 & 5.6 & 6.5 & 7.9 & 9.1 \\
\hline & & Medium & 0 & 1.9 & 2.9 & 4.1 & 5.2 & 6 & 7.1 & 8.7 \\
\hline & \multirow{2}{*}{ None pre-cooled } & Large & 0 & 3.3 & 3.5 & 5.9 & 7 & 8.1 & 9.2 & - \\
\hline & & Medium & 0 & 3.1 & 3.2 & 5.5 & 6.8 & 7.7 & 8.6 & - \\
\hline \multirow{4}{*}{ Defects, \% } & \multirow{2}{*}{ Pre-cooled } & Large & - & - & - & 7.8 & 22.1 & 34.2 & 58.4 & 88.2 \\
\hline & & Medium & - & - & - & 6.5 & 15.7 & 30.2 & 45.5 & 70.3 \\
\hline & \multirow{2}{*}{$\begin{array}{l}\text { None pre- } \\
\text { cooled. }\end{array}$} & Large & - & - & - & 17.5 & 48.9 & 80.9 & 100 & \\
\hline & & Medium & - & - & - & 14.7 & 38.9 & 70.8 & 85.2 & 100 \\
\hline \multirow{4}{*}{$\begin{array}{l}\text { Firmness, } \\
\mathrm{kg} / \mathrm{cm}^{2}\end{array}$} & \multirow{2}{*}{ Pre-cooled } & Large & 19.8 & 16.5 & 12.9 & 9.5 & 5.3 & 4.4 & 3.2 & 2.2 \\
\hline & & Medium & 20.1 & 17.1 & 14.3 & 11.9 & 7.5 & 5.8 & 4.1 & 2.7 \\
\hline & \multirow{2}{*}{ None pre-cooled } & Large & 19.8 & 14.1 & 10.2 & 6.9 & 3.5 & 2.5 & 1.5 & - \\
\hline & & Medium & 20.1 & 15.7 & 12.4 & 7.8 & 5.2 & 3.3 & 2.2 & - \\
\hline
\end{tabular}

\section{CONCLUSIONS}

1- The temperature of the peach fruits at the end position of the cooling chamber was always higher than the middle and fronts as well.

2-The values of cooling coefficient $(C)$ increased with the increase of air velocity $(\mathrm{V})$, increase of packages vents percentage, decrease of fruit volume and decrease of cooling air temperature.

3-The seven-eighth and half cooling times of peach fruits decreased with the increase of air velocity and increase of packages vents percentage while, they were increased with the increase of cooling temperature and increase of product volume.

4- Lower water loss, percentage of defect, and higher fruit firmness were observed for the pre-cooled samples in comparison with the none cooled samples for both storage conditions.

\section{REFERENCES}

Brosnan, T. and S., Da-Wen (2001). Pre-cooling techniques and applications for horticultural products- a review. International Journal of Refrigeration 24; 154-170.

Debney, H. G.; K. J., Blaker; B. J., Redding and J. B., Watkins (1980). Handling and storage practices for fresh fruits and vegetables. Abook Published by, Astralia United Fresh Fruits and Vegetables.

Fraser, H.W. (1992). Sizing and layout of a short-term refrigerated storage for fruits and vegetables. Factsheet. Ontario Ministry of Agriculture, food and Rural Affairs, I Stone Road West, Guelph.

Jordan, J.L.; S.E., Prussia; R.L., Shewfelt and J.C., Garner (1991). Economic impact of cooling delays on fruits and vegetables. Technical innovations in freezing and refrigeration of fruits and vegetables, 45-49.

Kader, A.A. (1993). Post harvest Handling. In: Preece, the Biology of Horticulture- An Introductory Textbook. New York: John Wiley \& Sons. p. 353 
Kalbasi-Ashtari, A. (2004). Effect of postharvest pre-cooling process and cyclical heat treatment on the physico-chemical properties of Red Haven peaches and Shahmiveh pears during cold storage. Agricultural engineering international: the CIGR journal of scientific research and development. Manuscript FP 04003. July.

Mitchell, F.G. (1992). Cooling horticultural commodities. In post harvest technology of horticultural crops, $2^{\text {nd }}$ Ed AA Kader, Cd. 53-68 Pub 3311. Davis: Univ. of California.

Ryall, A.I. and W.T., Pentzer (1982). Handling, transportation and storage of fruits and vegetables. Westport (CT): AVI Pub. Connecticut.

Shewfelt, R.L. (1986). Postharvest treatment for extending the shelf life of fruits and vegetables. Food Technology, 40 (5):7078 -7089.

Talbot, M.T. and K.V. Chau. (1991). Pre-cooling strawberries. Circular 942. IFAS. Gainesville. Fla, Univ. of Florida.

Talbot, M. T. (1993). Design and development of a portable forced-air cooler, Proceedings of Florida state Horticultural Society; 106: 246-255.

Thompson,,J.F.; M.F., Gordon; T.R. Rumsey; R.F. Kasmire, and C., Crisosto (1998). Commercial cooling of fruits, vegetables and flowers. University of Californian. Division of agricultural and natural resources, Publication No. 21567.

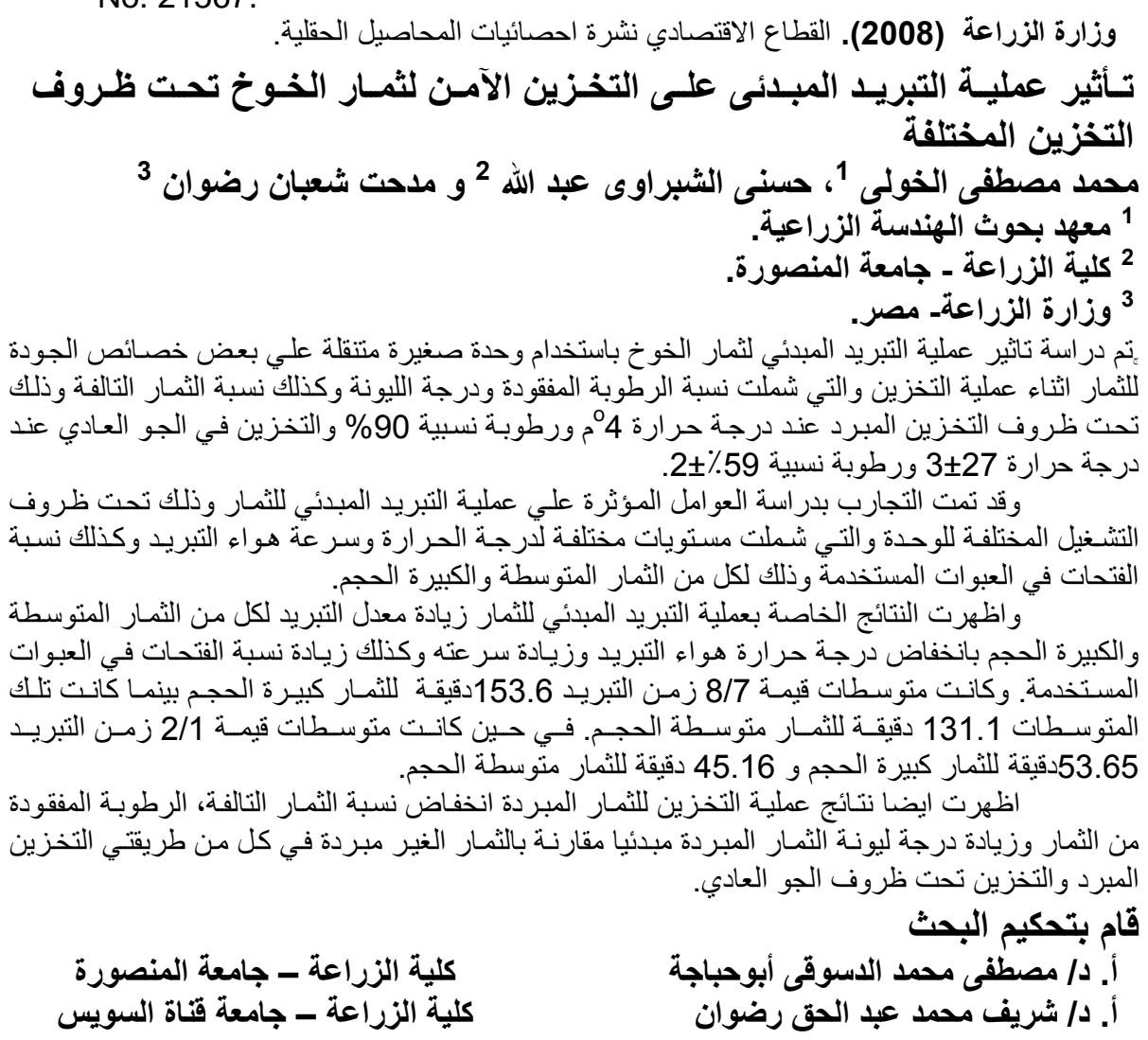


El-kholy, M. M. et al. 